\title{
Candida parapsilosis complex
}
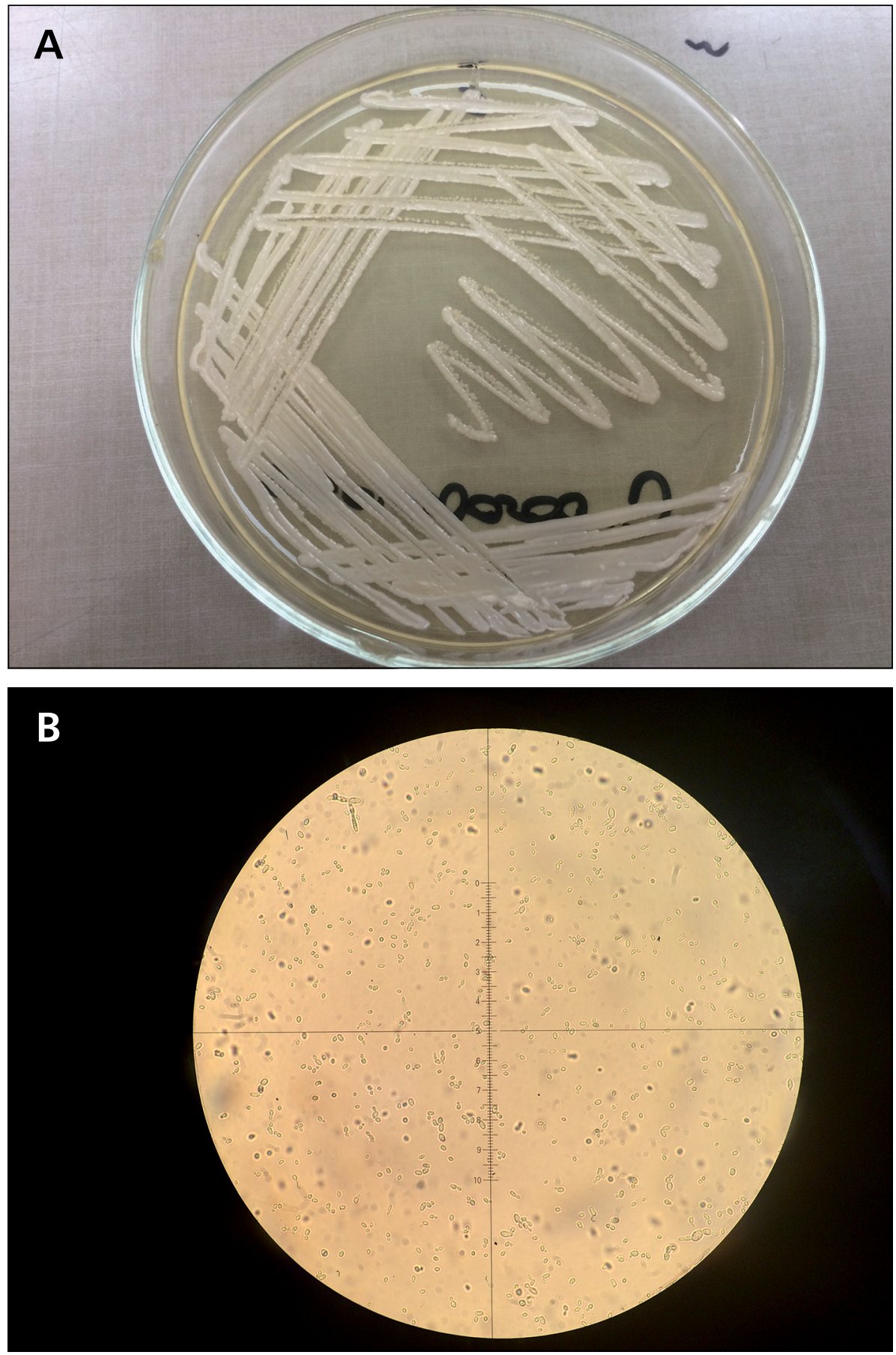

Figura 1. A) Candida parapsilosis sensu lato en agar Sabouraud. B) Examen directo de la colonia. Fotografías: Laboratorio de Micología Médica, Programa de Microbiología y Micología, Instituto de Ciencias Biomédicas, Facultad de Medicina, Universidad de Chile. 


\section{Candida parapsilosis complex}

Candida parapsilosis sensu lato (o en un sentido amplio) representa un complejo de hongos compuesto por tres especies genéticamente relacionadas que son: Candida parapsilosis sensu estricto (o en un sentido estricto), Candida orthosilopsis y Candida metapsilosis. Constituyen una importante causa de fungemia en todo el mundo (20-30\%) y cuya incidencia ha aumentado dramáticamente en los últimas dos décadas. En Chile, C. parapsilosis sensu lato constituye la segunda causa de candidemia. Este complejo fúngico se asocia a infecciones en recién nacidos y adultos jóvenes usualmente asociados a la presencia de dispositivos venosos centrales y alimentación parenteral ${ }^{1}$.

Taxonomía: Previamente, C. parapsilosis había sido investigada por su heterogeneidad intrínseca y la especie se clasificaba en tres biotipos, llamados I, II y III. Sin embargo, fue reclasificada el año 2005 por Tavanti y cols. en un complejo compuesto por las tres especies anteriormente mencionadas, siendo C. parapsilosis sensu stricto la especie predominante. Para ello, se utilizó la técnica llamada “multilocus sequence typing” (MLST)2.

Características microbiológicas e identificación: Los métodos utilizados habitualmente en los laboratorios de microbiología no pueden discriminar las especies del complejo y se basan más bien en la identificación bioquímica, dado que las tres especies presentan las mismas características morfológicas, de crecimiento y perfiles de asimilación y fermentación de azúcares. Aunque típicamente estas especies se observan de color blanco en CHROMagar Candida, se ha descrito la aparición de dos cepas de $C$. orthopsilosis con una pigmentación rosada en este medio, pudiendo confundirse con $C$. glabrata (colonia rosada) si no se realizan pruebas complementarias².

Las herramientas moleculares permiten la discriminación entre las especies del complejo. Pueden usarse métodos de biología molecular (intrón RPSO, inteína $V M A$ ), RPC-RFLP (genes $S A D H, F S K 1$ y $M n S O D$ ), (RPC en tiempo real (regiones ITS1, mtDNA, IGS1, gen $S A D H$ ), pirosecuenciación (región ITS2) y MALDI-TOF (proteínas) ${ }^{3}$. Recientemente, se ha demostrado que esta última metodología identifica correctamente las tres especies del complejo, siendo una herramienta promisoria para ser utilizada en los laboratorios de microbiología ${ }^{3}$.

Perfil de susceptibilidad: Candida parapsilosis sensu lato generalmente es susceptible a la mayoría de los fármacos antifúngicos aunque se han reportado infecciones causadas por aislados con susceptibilidad disminuida a azoles y equinocandinas. Se ha descrito también que existen diferencias entre las especies del complejo en cuanto a susceptibilidad antifúngica y virulencia. En general, el complejo C. parapsilosis presenta CIM más altas a equinocandinas, por lo que se han establecido distintos puntos de corte para esta familia de antifúngicos.

\section{Referencias bibliográficas}

1.- Ziccardi M, Souza L O, Gandra R M, Galdino A C, Baptista A R, Nunes A P, et al. Candida parapsilosis (sensu lato) isolated from hospitals located in the Southeast of Brazil: Species distribution, antifungal susceptibility and virulence attributes. Int J Med Microbiol 2015: S1438$4221(15) 30002-3$.

2.- Tavanti A, Davidson A D, Gow N A, Maiden M C, Odds F C. Candida orthopsilosis and Candida metapsilosis spp. nov. to replace Candida parapsilosis groups II and III. J Clin Microbiol 2005; 43: 284-92.

3.- Criseo G, Scordino F, Romeo O. Current methods for identifying clinically important cryptic Candida species. J Microbiol Methods. 2015; 111: 50-6.

Cecilia Tapia y Néstor Correa Laboratorio de Micología Médica, Programa de Microbiología y Micología, Instituto de Ciencias Biomédicas, Facultad de Medicina, Universidad de Chile. 